\title{
Association between physical frailty and quality of life in a representative sample of community-dwelling Swiss older people
}

Yves Henchoz ${ }^{1}$, Christophe Büla ${ }^{2}$, Idris Guessous ${ }^{1,3}$, Brigitte Santos-Eggimann ${ }^{1}$

${ }^{1}$ Institute of Social and Preventive Medicine, University of Lausanne Hospital Centre, Lausanne, Switzerland

${ }^{2}$ Service of Geriatric Medicine and Geriatric Rehabilitation, University of Lausanne Hospital Centre, Lausanne, Switzerland

${ }^{3}$ Unit of Population Epidemiology, Department of Community Medicine and Primary Care and Emergency Medicine, University Hospital of Geneva, Switzerland

Corresponding author: Yves Henchoz; Institute of Social and Preventive Medicine (IUMSP), University of Lausanne Hospital Centre, Route de la Corniche 10, CH-1010 Lausanne, Switzerland; yves.henchoz@chuv.ch; Tel.:+41 2131484 23; Fax: +41 213149767 


\begin{abstract}
Objective. Though the association between physical frailty and health is well established, little is known about its association with other domains of quality of life (QoL). This study investigated the association between physical frailty and multiple domains of QoL in community-dwelling older people.
\end{abstract}

Design. Cross-sectional study.

Setting and participants. Data of the 2011 annual assessment of 927 older people (age 73-77 years) from the Lc65+ cohort study were used.

Measurements. Physical frailty was assessed by Fried's five criteria: 'shrinking'; 'weakness'; 'poor endurance, exhaustion'; 'slowness'; and 'low activity'. QoL was assessed using 28 items yielding a QoL score and seven domain-specific QoL subscores (Feeling of safety; Health and mobility; Autonomy; Close entourage; Material resources; Esteem and recognition; and Social and cultural life). Low QoL (QoL score or QoL subscores in the lowest quintile) was used as dependent variable in logistic regression analyses adjusted for age and sex (model 1), and additionally for socioeconomic (model 2) and health (model 3) covariates.

Results. Physical frailty was associated with a low QoL score, as well as decreased QoL subscores in all seven specific domains, even after adjusting for socio-economic covariates. However, when performing additional adjustment for health covariates, only the domain Health and mobility remained significantly associated with physical frailty. Among each specific Fried's criteria, 'slowness' had the strongest association with a low QoL score.

Conclusion. Physical frailty is associated with all QoL domains, but these associations are largely explained by poor health characteristics. Longitudinal studies are needed to better understand temporal relationships between physical frailty, health and QoL.

Key words. Frailty; Quality of life; Aged; Health; Socioeconomic factors 


\section{INTRODUCTION}

Frailty is a state of increased vulnerability to stressors, following an acceleration of the gradual decrease in physiological reserve that occurs with aging (1). Cumulative declines across multiple physiological systems result in altered homeostatic mechanisms causing disproportionate changes in health status after minor stressor events (2). Frailty is a well-known risk factor for adverse outcomes of aging such as disability, falls, hospitalization and institutionalization (1, 3-7), and was even identified as the most common disorder leading to death (8). Among numerous frailty assessment tools, the two main models are the physical frailty phenotype operationalized in 2001 by Fried et al. based on 5 frailty criteria (1), and Rockwood's cumulative deficit model, where a frailty index is created based on a comprehensive geriatric assessment of individual deficits (9).

According to the World Health Organization, quality of life (QoL) is a broad ranging concept, incorporating in a complex way individuals' physical health, psychological state, level of independence, social relationships, personal beliefs and their relationships to salient features of the environment (10). Despite the multi-dimensional aspect of this QoL concept, most previous research focused on the relationship between physical frailty and health-related QoL. Studies using the Medical Outcomes Study Short Form-36 or Short Form-12 questionnaires reported lower scores of mental and physical health in frail compared to non-frail community dwelling older persons in the United States (11), Taiwan (12), Spain (13), Mexico (14) and Italy (15). In Dutch community dwelling older persons, physical frailty was significantly associated with social, psychological and physical functioning (16). A pragmatic randomized controlled trial indicated short-term improvement in health-related QoL after a client-centred and activity-oriented intervention program in frail community living older adults (17).

The association between frailty and a larger concept of QoL, that is not limited to health-related QoL but includes additional dimensions such as environmental-, financial-, or leisure activities-related QoL, has been addressed in only few studies. In a cross-sectional survey of 239 community-dwelling outpatients aged $65+(18)$, a negative association was found between physical frailty and five out of 
seven dimensions of the Older People's QoL questionnaire (health, independence, home and neighbourhood, psychological and emotional well-being, and leisure, activities and religion). Gobbens et al. used the World Health Organization QoL questionnaire in a series of studies on the Tilburg Frailty Indicator, a multidimensional self-report questionnaire assessing physical, psychological and social components of frailty $(19-21)$. Significant cross-sectional $(19,20)$ and longitudinal $(21)$ associations were reported between frailty and all four QoL domains. Finally, a significant inverse relationship was reported between the CASP-19 (control, autonomy, self-realization, pleasure) score and the extent of frailty in older people, as assessed using the frailty index (22) and the Chinese-Canadian study of health and aging clinical frailty scale (23).

Overall, these studies offer some evidence that physical frailty affects not only health-related QoL but also other QoL domains. However, the extent to which this association may be accounted for by mediators such as demographic, socioeconomic and health factors, remains unclear. Furthermore, the association between frailty and QoL domains has been analyzed using different frailty assessment tools, but never using Fried's criteria. Thus, the relationships between each one of the five criteria and the domains of QoL remain to be determined. Therefore, the present study primarily aimed to measure the association between physical frailty, defined according to Fried's frailty phenotype, and multiple domains of QoL in community-dwelling older people, and to determine whether these associations were independent from demographic, socioeconomic and health factors. A secondary aim was to explore the specific associations between each of the five frailty criteria and QoL domains. 


\section{METHODS}

\section{Population}

Data used in the present study came from the 2011 annual assessment of Lausanne cohort 65+ (LC65+)-a population-based study initiated in 2004 to investigate age-related frailty in old age (24). Enrolment in 2004 included 1,564 persons born in 1934-1938. In 2011, 1,107 individuals were still eligible for the present study, alive, living in Lausanne, and non-institutionalized, among which 1,067 (96.4\%) participated to the 2011 annual assessment. A total of 927 (83.7\%) participants with complete data for frailty assessment were included in the analysis. The protocol was approved by the Ethics Committee of the Faculty of Biology and Medicine of the University of Lausanne.

\section{Data collection}

Frailty criteria were collected during an in-person visit performed by trained research assistants following a standardized protocol (24). Information about QoL and demographic, socioeconomic and health covariates was collected through a postal questionnaire (25).

\section{Measures}

Physical frailty. According to Fried et al.'s phenotype (1), physical frailty was assessed using five criteria: 1) 'shrinking': any reported unintentional weight loss in prior year; 2) 'weakness': low grip strength according to Fried et al.'s (1) gender and body mass index specific cut-off values; 3) 'poor endurance, exhaustion": answering "much" to the question "did you have feelings of generalized weakness, weariness, lack of energy in the last four weeks?"; 4) 'slowness': slow gait speed according to Fried et al.'s (1) gender and height specific cut-off values; 5) 'low activity': <20 min of sport activity once a week, $<30$ min of walking 3 times a week and avoidance of climbing stairs or carrying light loads in daily activities. Subtle differences in the operationalization of physical frailty characteristics in the study of Fried et al. (1) and in the Lc65+ study were summarized previously (24). Based on the number of criteria fulfilled, participants were classified as "non-frail" (0 criterion), "pre-frail" (1-2 criteria) or "frail" ( $\geq 3$ criteria) as previously done (1). 
Quality of life (QoL). A 28-item QoL questionnaire was recently developed to reflect the convergence of health, social, cultural and economic factors of older people's QoL (see appendix 1) (25). A factorial structure comprising 7 QoL domains (Feeling of safety; Health and mobility; Autonomy; Close entourage; Material resources; Esteem and recognition; and Social and cultural life) was identified in an exploratory sample and confirmed in a validation sample, with adequate internal consistency within each domain (25). Respondents were asked to rate each item on its perceived discomfort or dissatisfaction ( $0=$ not at all, $1=a$ little, $2=a$ lot). A QoL score was calculated by summing answers to the 28 QoL items, dividing by 56 (maximum possible score), and multiplying by 100 so that the QoL score would range from 0 to 100, with higher scores indicating higher QoL. The same procedure was applied on the constituent items of each QoL domain to obtain its specific subscore. Low QoL was defined as a score below the first quintile for the QoL score as well as each domain-specific QoL subscores.

Covariates. Demographic variables included sex and age. Socioeconomic variables included Swiss citizenship, living arrangement ('alone'; 'with others'), highest level of education achieved ('basic compulsory'; 'apprenticeship'; 'post-compulsory'), and financial difficulties at the time of the study (defined as answering 'yes' to the question 'Are you sometimes struggling to make ends meet?'). Health variables included disability in basic activities of daily living (BADLs), the number of medical conditions, the presence of depressive symptoms and the cognitive status. To assess disability in BADLs, participants indicated whether they had difficulty or needed help with any of dressing, bathing, eating, getting in/out of bed or an arm-chair, and using the toilet during the past four weeks (26). To assess medical conditions, participants were asked whether they had suffered from symptoms or received treatment during the previous 12 months for any of 13 common health conditions, diagnosed by a physician: myocardial ischemia, heart disease, stroke, diabetes, chronic lung disease, asthma, osteoporosis, bone fracture, arthritis, malignant neoplasm, ulcer, Parkinson's disease and Alzheimer's disease. The number of reported medical conditions was categorised ('0'; ' 1 '; ' $\geq 2$ '). The presence of depressive symptoms was defined as a positive answer to either of the two following questions of the Primary Care Evaluation of Mental Disorders Procedure: “During the past month, have you often been 
bothered by 1) feeling down, depressed, or hopeless? 2) little interest or pleasure in doing things?". As compared to a standardized interview, these two questions had a sensitivity of $96 \%$ and a specificity of $57 \%$ in diagnosing depression (27). Cognitive status was assessed using the Mini-Mental State Examination (MMSE), which provides a score ranging from 0 to 30 with higher scores indicating better cognition (28).

\section{Statistical analysis}

Demographic, socioeconomic and health characteristics were compared across levels of Fried's physical frailty phenotype using Pearson Chi-squared tests, except age and MMSE score for which analysis of variance was used given the continuous nature of these variables. The association between physical frailty phenotype and QoL was assessed using multiple logistic regression analyses that were adjusted for age and sex (model 1), and additionally for socioeconomic covariates (model 2), and health covariates (model 3). These models were run for the QoL score and then separately for each domain-specific QoL subscores, using low QoL as dependent variable. Similarly, the associations between each individual frailty criteria and low QoL score and domain-specific QoL subscores were also assessed using models 1, 2 and 3. Given the exploratory nature of this secondary analysis, no formal adjustment for multiple comparisons was performed.

Because missing values were likely to be missing at random, missing data were imputed using multiple imputations with chained equations (29). Five imputation datasets were created. Repeated P-values of Pearson Chi-squared tests, as a result of multiple imputations, were combined using the procedure described by Li et al (30). Analyses were conducted using Stata 14.0 software (StataCorp, College Station, TX). Significance was set at $\mathrm{P}<0.05$. 


\section{RESULTS}

According to Fried's criteria, 603 participants were non-frail, 293 were pre-frail and 31 were frail. The prevalence of each physical frailty phenotype level was: non-frail $65.0 \%$ [95\% Confidence Interval (CI) 62.0-68.1]; pre-frail 31.6\% [95\% Cl 28.6-34.6]; and frail 3.3\% [95\% Cl 2.2-4.5]. The prevalence of each of the five frailty criteria was: 'shrinking' $12.0 \%$ [95\% Cl 9.9-14.1]; 'weakness' $20.0 \%$ [95\% Cl 17.4-22.6]; 'poor endurance, exhaustion' 5.5\% [95\% Cl 4.0-7.0]; 'slowness' 4.4\% [95\% Cl 3.1-5.8]; and 'low activity' $10.1 \%$ [95\% $\mathrm{Cl} 8.2-12.1]$. Characteristics of the study sample are indicated according to physical frailty phenotype in Table 1. Except for gender and citizenship, all other demographic, socioeconomic, and health characteristics differed across levels of physical frailty. Going from non-frail, to pre-frail and to frail, individuals were increasingly older, lived more frequently alone, had lower education, reported more frequently financial difficulties, disability in BADLs, multiple medical conditions and depressive symptoms, and had lower average MMSE score.

Results from the different multiple logistic regression models that analyzed the associations between physical frailty phenotype and a low QoL score are presented in Table 2. In model 1, adjusted for age and sex, pre-frailty $(O R=1.75 ; P=0.001)$ and frailty $(O R=6.83 ; P<0.001)$ were both associated with significantly increased odds of low QoL. The associations of pre-frailty $(O R=1.60 ; P=0.010)$ and frailty $(O R=5.71 ; P<0.001)$ status with a low QoL score remained significant but were slightly attenuated after adjustment for socioeconomic characteristics. Indeed, post-compulsory education $(\mathrm{OR}=0.50 ; \mathrm{P}=0.003$; basic education used as reference), and self-reported financial difficulties $(O R=2.49 ; P<0.001)$ were associated with increased odds of low QoL. In contrast, the relationships between pre-frailty and frailty status with a low QoL score disappeared in the final model that further adjusted for health characteristics. In this model, participants disabled in $B A D L s$ ( $O R=1.86 ; P=0.009$ ), those reporting depressive symptoms (OR=3.88; $\mathrm{P}<0.001)$, and those with financial difficulties $(\mathrm{OR}=2.67 ; \mathrm{P}<0.001)$ had about two to four times higher odds of low QoL. 
Table 3 indicates the associations between physical frailty phenotype and low domain-specific QoL subscores. Detailed associations with covariates are provided in Appendix 2 . In model 1 , frailty status was associated with higher odds of low QoL for all specific domains. A similar pattern was observed for pre-frailty status except for Close entourage and Esteem and recognition related QoL. In model 2, these associations remained essentially similar (one exception for Material resources related QoL where frailty status did not achieve statistical significance [OR=2.29; $P=0.050]$ ), but all ORs of low QoL were slightly attenuated. In model 3, associations between physical frailty phenotype and low QoL were not significant in six out of seven specific QoL domains. In the domain Health and mobility, the association was still significant for pre-frailty ( $O R=1.97 ; P=0.001)$ and frailty $(O R=3.26 ; P=0.025)$.

The association between each frailty criterion and low QoL is illustrated in Figure 1 for the QoL score and for each domain-specific QoL subscores. Regarding the QoL score, all individual criteria but 'shrinking' were significantly associated with low QoL in models 1 and 2. In contrast, after full adjustment, 'slowness' was the only criterion that remained significantly associated - with about twice higher odds ( $O R=2.62 ; P=0.018)$ - to a low QoL score. Finally, when looking at specific QoL domains, Health and mobility had the strongest association with each one of the five individual frailty criteria. 


\section{DISCUSSION}

This study investigated the cross-sectional association between physical frailty and QoL in a large representative sample of community-dwelling older people. An important contribution of this work is to provide original information on the relationships between physical frailty and QoL based on a multidimensional conceptual framework. In particular, the proposed analytic strategy that used models with successive adjustment for additional dimensions allows to better understanding these relationships. Specifically, although physical frailty remained associated with a low QoL score and with low domain-specific QoL subscores when adjusting only for age and sex, the present results show that the strength of these associations decreased once adjusting further for socioeconomic factors, and disappeared when further adjusting for health covariates.

These observations extend those of previous studies that reported an association between physical frailty and QoL $(18,20)$ in showing in more detail the interplay between frailty, demographic, socioeconomic, and health dimensions in their relationship with QoL. These results also add to previous observations such as the English Longitudinal Study of Aging that indicated a dose-response relationship between financial resources and subjective well-being, which did not significantly impact the association between physical frailty and subjective well-being (22). Finally, these results further emphasize the importance of health factors, such as disability in BADLs and depression, as major confounders in the association between physical frailty and QoL. Because physical frailty contributes to the incidence or progression of disability and comorbidity $(5,31)$, it appears that physical frailty does not affect most domains of QoL so long as it does not develop into disability and comorbidity.

Among specific QoL domains, Health and mobility was the only one whose association with physical frailty remained after full adjustment, even though it was substantially decreased. These results extend those of Bilotta et al. who reported a significant association between disability in BADLs, depression and QoL (18) in suggesting a direct association between physical frailty and health-related QoL. In contrast, the loss of significance between physical frailty and the other specific QoL domains 
supports the hypothesis of an indirect association between physical frailty and other QoL domains, with disability in BADLs and depression as mediators. Interestingly, "feeling down", a component of psychological frailty in the Tilburg Frailty Indicator, was also strongly associated with all four QoL domains of the World Health Organization QoL questionnaire (20).

In addition, this study extends previous work in providing detailed information on the specific relationships between each individual criteria of Fried's physical frailty phenotype and QoL as well as domain-specific QoL. An original contribution is certainly to enrich previous observations on the importance of gait speed not only as a marker of health but also as a strong indicator of QoL. Indeed, 'slowness' was the only criterion that remained independently associated with a low QoL score once adjusting for health covariates in addition to age, gender, and socio-economic characteristics. Moreover, 'slowness' also showed the strongest association with a low QoL in the specific Health and mobility domain, even stronger than 'poor endurance, exhaustion'. 'Slowness' has been reported as the criterion most related to the physical component of health-related QoL in two previous studies $(32,14)$, whereas 'poor endurance, exhaustion' was consistently reported as the criterion most related to the mental component $(32,12,14,15)$. These results add to the body of evidence supporting gait speed as an important measure in comprehensive geriatric assessment, with well-documented predictive value for adverse outcomes of aging such as hospitalization, institutionalization, mortality and falls (33). Castell et al. reported that a gait speed of $0.9 \mathrm{~m} / \mathrm{s}$ or more rules out the presence of physical frailty, and that a gait speed of $0.8 \mathrm{~m} / \mathrm{s}$ or less doubles the probability of the presence of physical frailty (34). Even though the present study could not determine the precise interplay between gait speed and QoL, results emphasize the clinical relevance of 'slowness' among Fried's criteria as an important health and QoL indicator. Slow gait speed is an indicator of physical function impairment, which has recently been highlighted as the convergence between physical frailty and sarcopenia (35, 36). Simple tests, such as usual gait speed, have been advocated in the clinical setting to identify older persons at risk of both frailty and sarcopenia (37). 
Another interesting finding is the lack of association observed between 'shrinking' and QoL. Indeed, 'shrinking' was the only criterion that lacked significant association with a low QoL score, as well as all but one domain-specific QoL subscores. In fact, 'shrinking' had the weakest association with Health and mobility-related QoL. In three previous studies, 'shrinking' was the only criterion not significantly associated with the physical and the mental components of health-related QoL $(12,15,32)$. MorenoAguilar et al. reported a significant association between 'shrinking' and the mental component of health-related QoL, but not with the physical component (14).

A major strength of this study is to relate on data from the Lc65+ study. This cohort includes a large and representative sample of community-dwelling older people, and collects extensive data that allowed to adjusting for a substantial number of potential confounders, combining both self-report and objective measures. Furthermore, a global definition of QoL was used, whereas previous studies assessing frailty using Fried's criteria were restricted to health-related QoL. Some limitations must also be mentioned. First, the cross-sectional design precludes any causal inference. Although physical frailty is more likely to be a cause rather than a consequence of low QoL, it can also be postulated that low QoL may lead to behavioural and physiological adaptations favouring the development of physical frailty. Second, the prevalence of physical frailty (i.e. 3.3\%) was small compared to an average of $10.7 \%$ in previous studies (38). This may be explained by a lower frequency of physical frailty reported in Switzerland compared to other European countries (39), as well as in studies using the Fried's phenotype compared to the cumulative deficit model (38). Third, because no adjustment for multiple comparisons was made, associations between frailty criteria and QoL were interpreted cautiously to avoid overinterpretation. However, given the large sample size, most associations would resist very conservative adjustment for multiple testing (e.g. Bonferroni's correction). Finally, whereas the present study focused on physical frailty, other conceptual definitions include additional dimensions, such as social and psychological frailty $(19,40)$, whose association with multiple domains of QoL may be addressed in future studies. Cognitive frailty, a new clinical concept in the Geriatrics literature, also opens new research avenues (41). 
In conclusion, this study indicated significant associations between physical frailty and decreased global as well as domain-specific QoL. These results add to evidence supporting the development and strengthening of strategies targeting the primary and secondary prevention of age-related frailty. Longitudinal studies on the temporal trajectories of QoL in relation to physical frailty will lend further support to this strategy. Because health covariates seem to mediate the association between physical frailty and QoL, managing health consequences of physical frailty is likely to also contribute to improving other domains of older people's life.

\section{ETHICAL STANDARDS}

The experiments comply with current laws of Switzerland in which the study was performed. The protocol was approved by the Ethics Committee of the Faculty of Biology and Medicine of the University of Lausanne.

\section{FUNDING}

This work was supported by a prize awarded by the Leenaards Foundation.

\section{CONFLICT OF INTEREST}

The authors have no conflict of interest to declare. 


\section{REFERENCES}

1. Fried LP, Tangen CM, Walston J, et al. Frailty in older adults: evidence for a phenotype. J Gerontol A Biol Sci Med Sci 2001;56(3): M146-156.

2. Clegg A, Young J, lliffe S, Rikkert MO, Rockwood K. Frailty in elderly people. Lancet 2013;381(9868): 752-762. doi: 10.1016/S0140-6736(12)62167-9

3. Bandeen-Roche K, Xue QL, Ferrucci L, et al. Phenotype of frailty: characterization in the women's health and aging studies. J Gerontol A Biol Sci Med Sci 2006;61(3): 262-266.

4. Abizanda P, Romero L, Sanchez-Jurado PM, Martinez-Reig M, Gomez-Arnedo L, Alfonso SA. Frailty and mortality, disability and mobility loss in a Spanish cohort of older adults: the FRADEA study. Maturitas 2013;74(1): 54-60. doi: 10.1016/j.maturitas.2012.09.018

5. Makizako H, Shimada H, Doi T, Tsutsumimoto K, Suzuki T. Impact of physical frailty on disability in community-dwelling older adults: a prospective cohort study. BMJ Open 2015;5(9): e008462. doi: 10.1136/bmjopen-2015-008462

6. Rockwood K, Howlett SE, MacKnight C, et al. Prevalence, attributes, and outcomes of fitness and frailty in community-dwelling older adults: report from the Canadian study of health and aging. J Gerontol A Biol Sci Med Sci 2004;59(12): 1310-1317.

7. Ensrud KE, Ewing SK, Taylor BC, et al. Comparison of 2 frailty indexes for prediction of falls, disability, fractures, and death in older women. Arch Intern Med 2008;168(4): 382-389. doi: 10.1001/archinternmed.2007.113

8. Gill TM, Gahbauer EA, Han L, Allore HG. Trajectories of disability in the last year of life. N Engl J Med 2010;362(13): 1173-1180. doi: 10.1056/NEJMoa0909087

9. Rockwood K, Mitnitski A. Frailty defined by deficit accumulation and geriatric medicine defined by frailty. Clin Geriatr Med 2011;27(1): 17-26. doi: 10.1016/j.cger.2010.08.008

10. WHO. The World Health Organization Quality of Life assessment (WHOQOL): position paper from the World Health Organization. Soc Sci Med 1995;41(10): 1403-1409.

11. Masel MC, Graham JE, Reistetter TA, Markides KS, Ottenbacher KJ. Frailty and health related quality of life in older Mexican Americans. Health Qual Life Outcomes 2009;7: 70. doi: 10.1186/1477-7525-7-70

12. Lin $\mathrm{CC}$, $\mathrm{Li} \mathrm{Cl}$, Chang $\mathrm{CK}$, et al. Reduced health-related quality of life in elders with frailty: a crosssectional study of community-dwelling elders in Taiwan. PLoS One 2011;6(7): e21841. doi: 10.1371/journal.pone.0021841

13. Jurschik $P$, Nunin $C$, Botigue $T$, Escobar MA, Lavedan A, Viladrosa M. Prevalence of frailty and factors associated with frailty in the elderly population of Lleida, Spain: the FRALLE survey. Arch Gerontol Geriatr 2012;55(3): 625-631. doi: 10.1016/j.archger.2012.07.002

14. Moreno-Aguilar M, García-Lara JMA, Aguilar-Navarro S, Navarrete-Reyes AP, Amieva H, AvilaFunes JA. The phenotype of frailty and health-related quality of life. J Frailty Aging 2013;2(1): 2-7.

15. Mulasso A, Roppolo $M$, Rabaglietti $E$. The role of individual characteristics and physical frailty on health related quality of life (HRQOL): a cross sectional study of Italian community-dwelling older adults. Arch Gerontol Geriatr 2014;59(3): 542-548. doi: 10.1016/j.archger.2014.08.012

16. Op Het Veld LP, van Rossum E, Kempen GI, de Vet HC, Hajema K, Beurskens AJ. Fried phenotype of frailty: cross-sectional comparison of three frailty stages on various health domains. BMC Geriatr 2015;15: 77. doi: 10.1186/s12877-015-0078-0 
17. De Vriendt $\mathrm{P}$, Peersman $\mathrm{W}$, Florus $\mathrm{A}$, Verbeke $\mathrm{M}$, Van de Velde D. Improving Health Related Quality of Life and Independence in Community Dwelling Frail Older Adults through a ClientCentred and Activity-Oriented Program. A Pragmatic Randomized Controlled Trial. J Nutr Health Aging 2016;20(1): 35-40. doi: 10.1007/s12603-015-0581-1

18. Bilotta C, Bowling A, Case A, et al. Dimensions and correlates of quality of life according to frailty status: a cross-sectional study on community-dwelling older adults referred to an outpatient geriatric service in Italy. Health Qual Life Outcomes 2010;8: 56. doi: 10.1186/1477-7525-8-56

19. Gobbens RJ, van Assen MA, Luijkx KG, Schols JM. Testing an integral conceptual model of frailty. J Adv Nurs 2012;68(9): 2047-2060. doi: 10.1111/j.1365-2648.2011.05896.x

20. Gobbens RJ, Luijkx KG, van Assen MA. Explaining quality of life of older people in the Netherlands using a multidimensional assessment of frailty. Qual Life Res 2013;22(8): 2051-2061. doi: $10.1007 / \mathrm{s} 11136-012-0341-1$

21. Gobbens RJ, van Assen MA. The prediction of quality of life by physical, psychological and social components of frailty in community-dwelling older people. Qual Life Res 2014;23(8): 2289-2300. doi: $10.1007 /$ s11136-014-0672-1

22. Hubbard RE, Goodwin VA, Llewellyn DJ, Warmoth K, Lang IA. Frailty, financial resources and subjective well-being in later life. Arch Gerontol Geriatr 2014;58(3): 364-369. doi: 10.1016/j.archger.2013.12.008

23. Wu TY, Chie WC, Kuo KL, et al. Quality of life (QOL) among community dwelling older people in Taiwan measured by the CASP-19, an index to capture QOL in old age. Arch Gerontol Geriatr 2013;57(2): 143-150. doi: 10.1016/j.archger.2013.03.010

24. Santos-Eggimann B, Karmaniola A, Seematter-Bagnoud L, et al. The Lausanne cohort Lc65+: a population-based prospective study of the manifestations, determinants and outcomes of frailty. BMC Geriatr 2008;8: 20. doi: 10.1186/1471-2318-8-20

25. Henchoz Y, Meylan L, Goy R, et al. Domains of importance to the quality of life of older people from two Swiss regions. Age Ageing 2015;44(6): 979-985. doi: 10.1093/ageing/afv130

26. Katz S, Downs TD, Cash HR, Grotz RC. Progress in development of the index of ADL. Gerontologist 1970;10(1): 20-30.

27. Whooley MA, Avins AL, Miranda J, Browner WS. Case-finding instruments for depression. Two questions are as good as many. J Gen Intern Med 1997;12(7): 439-445.

28. Folstein MF, Folstein SE, McHugh PR. "Mini-mental state". A practical method for grading the cognitive state of patients for the clinician. J Psychiatr Res 1975;12(3): 189-198.

29. White IR, Royston $P$, Wood AM. Multiple imputation using chained equations: Issues and guidance for practice. Stat Med 2011;30(4): 377-399. doi: 10.1002/sim.4067

30. Li KH, Meng XL, Raghunathan TE, Rubin DB. Significance levels from repeated $p$-values with multiply-imputed data. Stat Sin 1991;1(1): 65-92.

31. Fried LP, Ferrucci L, Darer J, Williamson JD, Anderson G. Untangling the concepts of disability, frailty, and comorbidity: implications for improved targeting and care. J Gerontol A Biol Sci Med Sci 2004;59(3): 255-263.

32. Chang YW, Chen WL, Lin FG, et al. Frailty and its impact on health-related quality of life: a crosssectional study on elder community-dwelling preventive health service users. PLoS One 2012;7(5): e38079. doi: 10.1371/journal.pone.0038079

33. Peel NM, Kuys SS, Klein K. Gait speed as a measure in geriatric assessment in clinical settings: a systematic review. J Gerontol A Biol Sci Med Sci 2013;68(1): 39-46. doi: 10.1093/gerona/gls174 
34. Castell MV, Sanchez M, Julian R, Queipo R, Martin S, Otero A. Frailty prevalence and slow walking speed in persons age 65 and older: implications for primary care. BMC Fam Pract 2013;14: 86. doi: $10.1186 / 1471-2296-14-86$

35. Calvani R, Marini F, Cesari M, et al. Biomarkers for physical frailty and sarcopenia: state of the science and future developments. J Cachexia Sarcopenia Muscle 2015;6(4): 278-286. doi: 10.1002/jcsm.12051

36. Cesari M, Landi F, Vellas B, Bernabei R, Marzetti E. Sarcopenia and physical frailty: two sides of the same coin. Front Aging Neurosci 2014;6: 192. doi: 10.3389/fnagi.2014.00192

37. Keevil VL, Romero-Ortuno R. Ageing well: a review of sarcopenia and frailty. Proc Nutr Soc 2015;74(4): 337-347. doi: 10.1017/S0029665115002037

38. Collard RM, Boter H, Schoevers RA, Oude Voshaar RC. Prevalence of frailty in community-dwelling older persons: a systematic review. J Am Geriatr Soc 2012;60(8): 1487-1492. doi: 10.1111/j.15325415.2012.04054.x

39. Santos-Eggimann B, Cuenoud P, Spagnoli J, Junod J. Prevalence of frailty in middle-aged and older community-dwelling Europeans living in 10 countries. J Gerontol A Biol Sci Med Sci 2009;64(6): 675-681. doi: 10.1093/gerona/glp012

40. Peters LL, Boter H, Buskens E, Slaets JP. Measurement properties of the Groningen Frailty Indicator in home-dwelling and institutionalized elderly people. J Am Med Dir Assoc 2012;13(6): 546-551. doi: 10.1016/j.jamda.2012.04.007

41. Fitten LJ. Thinking about cognitive frailty. J Prev Alzheimers Dis 2015;2(1): 7-10. 
Table 1. Characteristics of study participants according to physical frailty status.

\begin{tabular}{lllll}
\hline Characteristics & $\begin{array}{l}\text { Total sample } \\
(\mathrm{N}=927)\end{array}$ & & \multicolumn{2}{c}{ Physical frailty status } \\
\cline { 2 - 4 } & & & \\
\cline { 2 - 4 } & & $\begin{array}{l}\text { Non-frail } \\
(\mathrm{N}=603)\end{array}$ & $\begin{array}{l}\text { Pre-frail } \\
(\mathrm{N}=293)\end{array}$ & $\begin{array}{l}\text { Frail } \\
(\mathrm{N}=31)\end{array}$ \\
\hline
\end{tabular}

\section{Demographic}

\begin{tabular}{|c|c|c|c|c|c|}
\hline Females (\%) & $60.3 \%$ & $58.1 \%$ & $63.5 \%$ & $74.2 \%$ & $0.082^{\dagger}$ \\
\hline Age (mean (SE)) & $75.0(0.1)$ & $74.9(0.1)$ & $75.0(0.1)$ & $75.8(0.2)$ & $<0.001^{\ddagger}$ \\
\hline Age (range) & $73-77$ & $73-77$ & $73-77$ & $73-77$ & \\
\hline \multicolumn{6}{|l|}{ Socioeconomic } \\
\hline Swiss citizenship (\%) & $90.4 \%$ & $91.6 \%$ & $88.0 \%$ & $90.3 \%$ & $0.081^{\dagger}$ \\
\hline Living alone (\%) & $41.2 \%$ & $38.6 \%$ & $45.1 \%$ & $54.8 \%$ & $0.015^{\dagger}$ \\
\hline \multicolumn{6}{|l|}{ Education (\%) } \\
\hline Basic compulsory & $22.4 \%$ & $20.4 \%$ & $25.3 \%$ & $32.3 \%$ & $0.038^{+}$ \\
\hline Apprenticeship & $40.2 \%$ & $40.2 \%$ & $39.5 \%$ & $45.2 \%$ & \\
\hline Post-compulsory & $37.5 \%$ & $39.3 \%$ & $35.2 \%$ & $22.6 \%$ & \\
\hline Financial difficulties (\%) & $12.3 \%$ & $9.9 \%$ & $15.4 \%$ & $29.7 \%$ & $<0.001^{\dagger}$ \\
\hline \multicolumn{6}{|l|}{ Health } \\
\hline Disability in BADLs (\%) & $15.5 \%$ & $8.3 \%$ & $25.3 \%$ & $64.5 \%$ & $<0.001^{\dagger}$ \\
\hline \multicolumn{6}{|l|}{ Medical conditions (\%) } \\
\hline 0 & $28.7 \%$ & $35.2 \%$ & $18.1 \%$ & $3.2 \%$ & $<0.001^{\dagger}$ \\
\hline 1 & $35.6 \%$ & $38.1 \%$ & $32.4 \%$ & $16.1 \%$ & \\
\hline$\geq 2$ & $35.7 \%$ & $26.7 \%$ & $49.5 \%$ & $80.6 \%$ & \\
\hline Depressive symptoms (\%) & $25.4 \%$ & $17.6 \%$ & $36.3 \%$ & $74.2 \%$ & $<0.001^{+}$ \\
\hline MMSE score (mean (SE)) & $27.3(0.1)$ & $27.4(0.1)$ & $26.6(0.1)$ & $25.3(0.5)$ & $<0.001^{\ddagger}$ \\
\hline
\end{tabular}

${ }^{\dagger}$ Pearson Chi-squared test $;{ }^{\ddagger}$ Analysis of variance; SE = standard error; BADLs = basic activities of daily living; MMSE = Mini-Mental State Examination 
Table 2. Association between physical frailty status and low quality of life using multiple logistic regression.

\section{Low quality of life score}

\begin{tabular}{lll}
\hline Model 1 & Model 2 & Model 3 \\
OR $(95 \% \mathrm{Cl})$ & OR $(95 \% \mathrm{Cl})$ & OR $(95 \% \mathrm{Cl})$ \\
\hline
\end{tabular}

\begin{tabular}{llll}
\hline Physical frailty (ref: non-frail) & & & \\
$\quad$ Pre-frail & $1.75(1.24-2.47) * *$ & $1.60(1.12-2.30) *$ & $0.98(0.65-1.48)$ \\
$\quad$ Frail & $6.83(3.15-14.83) * * *$ & $5.71(2.76-11.83) * * *$ & $1.54(0.64-3.72)$ \\
Age & $0.96(0.85-1.08)$ & $0.95(0.84-1.07)$ & $0.93(0.82-1.07)$ \\
Females (ref: males) & $1.42(1.00-2.00)$ & $1.40(0.95-2.05)$ & $1.27(0.84-1.92)$ \\
Swiss citizenship (ref: no) & & $0.62(0.36-1.09)$ & $0.65(0.34-1.24)$ \\
Living alone (ref: with others) & $0.94(0.65-1.34)$ & $0.85(0.58-1.25)$ \\
Education (ref: basic) & & \\
$\quad$ Apprenticeship & & $0.80(0.52-1.22)$ & $0.98(0.61-1.58)$ \\
Post-compulsory & $0.50(0.32-0.79) * *$ & $0.62(0.38-1.02)$ \\
Financial difficulties (ref: no) & $2.49(1.57-3.95) * * *$ & $2.67(1.65-4.33) * * *$ \\
Disability in BADLs (ref: no) & & $1.86(1.17-2.94) * *$ \\
Medical conditions (ref: 0$)$ & & $1.34(0.81-2.22)$ \\
1 & & & $1.64(1.00-2.70)$ \\
$\geq 2$ & & $3.88(2.63-5.72) * * *$ \\
Depression (ref: no) & & $0.93(0.85-1.01)$ \\
MMSE & & &
\end{tabular}

${ }^{*} \mathrm{P}<.05 ;{ }^{*} \mathrm{P}<.01 ;{ }^{* *} \mathrm{P}<.001 ; \mathrm{OR}=$ odds ratios; $\mathrm{Cl}=$ confidence intervals; $\mathrm{BADLs}=$ basic activities of daily living; $M M S E$ = Mini-Mental State Examination; low quality of life defined as a score below the $1^{\text {st }}$ quintile; Model 1: adjusted for age and sex; Model 2: adjusted for covariates in Model 1 and socioeconomic variables; Model 3: adjusted for covariates in Model 2 and health variables. 
Table 3. Associations between physical frailty status and low domain-specific quality of life using multiple logistic regression.

\begin{tabular}{|c|c|c|c|}
\hline \multirow{3}{*}{$\begin{array}{l}\text { Physical frailty } \\
\text { status } \\
\text { (ref: non-frail) }\end{array}$} & \multicolumn{3}{|c|}{ Low domain-specific quality of life subscores } \\
\hline & Model 1 & Model 2 & Model 3 \\
\hline & OR $(95 \% \mathrm{Cl})$ & OR $(95 \% \mathrm{Cl})$ & OR $(95 \% \mathrm{Cl})$ \\
\hline & \multicolumn{3}{|l|}{ Domain Feeling of safety } \\
\hline Pre-frail & $1.82(1.27-2.62) * *$ & $1.62(1.10-2.38) *$ & $1.13(0.72-1.76)$ \\
\hline \multirow[t]{2}{*}{ Frail } & $3.39(1.49-7.72) * *$ & $2.41(1.03-5.63) *$ & $0.78(0.27-2.23)$ \\
\hline & \multicolumn{3}{|c|}{ Domain Health and mobility } \\
\hline Pre-frail & $3.14(2.19-4.50) * * *$ & $3.01(2.07-4.36) * * *$ & $1.97(1.31-2.94) * *$ \\
\hline \multirow[t]{2}{*}{ Frail } & $11.56(5.18-25.80) * * *$ & $11.22(4.88-25.81) * * *$ & $3.26(1.16-9.13) *$ \\
\hline & \multicolumn{3}{|l|}{ Domain Autonomy } \\
\hline Pre-frail & $1.76(1.25-2.49) * *$ & $1.68(1.17-2.40) * *$ & $1.19(0.80-1.78)$ \\
\hline \multirow[t]{2}{*}{ Frail } & $4.94(2.23-10.90) * * *$ & $4.29(2.02-9.12) * * *$ & $1.79(0.75-4.25)$ \\
\hline & \multicolumn{3}{|l|}{ Domain Close entourage } \\
\hline Pre-frail & $1.42(1.00-2.02)$ & $1.33(0.92-1.91)$ & $1.01(0.66-1.54)$ \\
\hline \multirow[t]{2}{*}{ Frail } & $5.39(2.42-12.02) * * *$ & $4.80(2.16-10.64) * * *$ & $2.16(0.86-5.42)$ \\
\hline & \multicolumn{3}{|c|}{ Domain Material resources } \\
\hline Pre-frail & $1.68(1.18-2.39) * *$ & $1.46(1.00-2.14) *$ & $1.14(0.76-1.73)$ \\
\hline \multirow[t]{2}{*}{ Frail } & $2.98(1.37-6.48) * *$ & $2.29(1.00-5.25)$ & $1.24(0.46-3.32)$ \\
\hline & \multicolumn{3}{|c|}{ Domain Esteem and recognition } \\
\hline Pre-frail & $1.24(0.88-1.74)$ & $1.18(0.83-1.67)$ & $0.83(0.56-1.21)$ \\
\hline \multirow[t]{2}{*}{ Frail } & $2.60(1.16-5.83) *$ & $2.28(1.05-4.95) *$ & $0.84(0.33-2.14)$ \\
\hline & \multicolumn{3}{|c|}{ Domain Social and cultural life } \\
\hline Pre-frail & $1.72(1.23-2.42) * *$ & $1.66(1.17-2.34) * *$ & $1.26(0.85-1.87)$ \\
\hline Frail & $3.48(1.55-7.79) * *$ & $3.03(1.38-6.65) * *$ & $1.53(0.60-3.89)$ \\
\hline
\end{tabular}

${ }^{*} \mathrm{P}<.05 ;{ }^{*} \mathrm{P}<.01 ;{ }^{* *} \mathrm{P}<.001 ; \mathrm{OR}=$ odds ratios; $\mathrm{Cl}=$ confidence intervals; low quality of life defined as a score below the $1^{\text {st }}$ quintile; Model 1: adjusted for age and sex; Model 2: adjusted for covariates in Model 1 and socioeconomic variables; Model 3: adjusted for covariates in Model 2 and health variables. 

exhaustion

QoL score
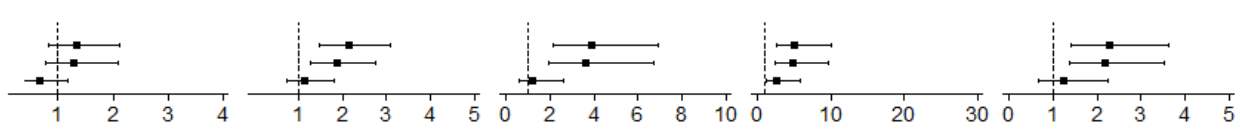

Domain-specific QoL subscores
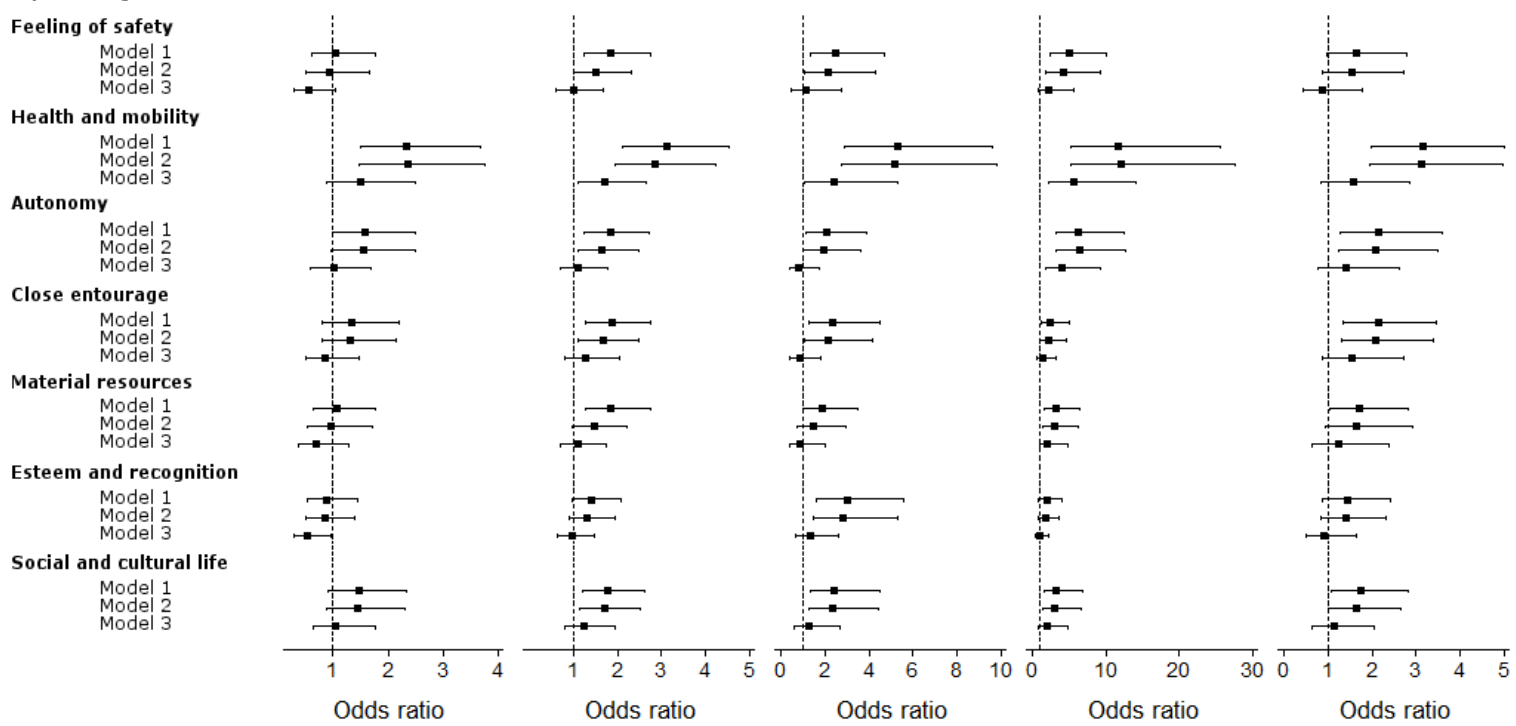

Figure 1. Association between physical frailty components and low quality of life using multiple logistic regression; QoL = quality of life; Model 1: adjusted for age and sex; Model 2: adjusted for covariates in Model 1 and socioeconomic variables; Model 3: adjusted for covariates in Model 2 and health variables. 
Appendix 1. List of 28 quality of life items.

\begin{tabular}{|c|c|}
\hline Quality of Life domains & Item number \\
\hline \multirow[t]{4}{*}{ Feeling of safety } & 20. Safety at home \\
\hline & 21. Safety in the street \\
\hline & 19. Adequate health insurance coverage \\
\hline & 18. Access to health care and prevention \\
\hline \multirow[t]{5}{*}{ Health and mobility } & 14. Mobility, being able to travel alone \\
\hline & 15. Being able to use public transport alone \\
\hline & 16. Being able to travel \\
\hline & 13. Not being dependent on help in daily life \\
\hline & 17. Physical and mental health \\
\hline \multirow[t]{5}{*}{ Autonomy } & 27. Being able to express one's opinion, to vote, etc. \\
\hline & 28. Being well informed to meet one's needs and decide \\
\hline & 26. Being useful to others \\
\hline & 25. Being able to manage money matters alone \\
\hline & 24. Being able to decide on issues of daily life \\
\hline \multirow[t]{5}{*}{ Close entourage } & 6. Family relationships \\
\hline & 5. Couples' relationships \\
\hline & 4. Friendly atmosphere meals \\
\hline & 8. Intergenerational relationships \\
\hline & 7. Friendship relationships \\
\hline \multirow[t]{3}{*}{ Material resources } & 2. Housing comfort \\
\hline & 1. Financial resources \\
\hline & 3. Sufficient, good quality food \\
\hline \multirow[t]{2}{*}{ Esteem and recognition } & 10. Self-esteem \\
\hline & 11. Being heard and respected \\
\hline \multirow[t]{4}{*}{ Social and cultural life } & 9. Integration into a group, association or society \\
\hline & 12. Cultural and leisure activities \\
\hline & 22. Religion, philosophy or spiritual life \\
\hline & 23. Being able to exercise one's creativity, share ideas \\
\hline
\end{tabular}


Appendix 2. Multiple logistic regression models with covariates.

\begin{tabular}{|c|c|c|c|}
\hline & \multicolumn{3}{|c|}{ Low quality of life subscore (domain Feeling of safety) } \\
\hline & Model 1: OR (95\% Cl) & Model 2: OR (95\% Cl) & Model 3: OR (95\% Cl) \\
\hline \multicolumn{4}{|l|}{ Physical frailty (ref: non-frail) } \\
\hline Pre-frail & $1.82(1.27-2.62) * *$ & $1.62(1.10-2.38) *$ & $1.13(0.72-1.76)$ \\
\hline Frail & $3.39(1.49-7.72) * *$ & $2.41(1.03-5.63) *$ & $0.78(0.27-2.23)$ \\
\hline Age & $1.03(0.91-1.17)$ & $1.02(0.89-1.16)$ & $1.00(0.87-1.16)$ \\
\hline Females (ref: males) & $1.28(0.89-1.85)$ & $1.04(0.69-1.58)$ & $1.07(0.69-1.65)$ \\
\hline Swiss citizenship (ref: no) & & $0.92(0.49-1.71)$ & $1.00(0.51-1.97)$ \\
\hline Living alone (ref: with others) & & $1.47(0.99-2.18)$ & $1.40(0.93-2.11)$ \\
\hline \multicolumn{4}{|l|}{ Education (ref: basic) } \\
\hline Apprenticeship & & $0.81(0.50-1.29)$ & $0.96(0.58-1.58)$ \\
\hline Post-compulsory & & $0.49(0.30-0.80) * *$ & $0.62(0.37-1.04)$ \\
\hline Financial difficulties (ref: no) & & $4.25(2.62-6.91) * * *$ & $4.61(2.74-7.74) * * *$ \\
\hline Disability in BADLs (ref: no) & & & $2.34(1.44-3.81) * *$ \\
\hline \multicolumn{4}{|l|}{ Medical conditions (ref: 0) } \\
\hline 1 & & & $1.52(0.92-2.51)$ \\
\hline$\geq 2$ & & & $1.24(0.72-2.13)$ \\
\hline Depression (ref: no) & & & $1.80(1.17-2.78) * *$ \\
\hline MMSE & & & $0.91(0.84-0.99) *$ \\
\hline
\end{tabular}

${ }^{*} \mathrm{P}<.05 ;{ }^{*} \mathrm{P}<.01 ;{ }^{*} * \mathrm{P}<.001 ; \mathrm{OR}=$ odds ratios; $\mathrm{Cl}=$ confidence intervals; $\mathrm{BADLs}=$ basic activities of daily living; MMSE = Mini-Mental State Examination; low quality of life defined as a score below the $1^{\text {st }}$ quintile. 
Appendix 2. (Continued)

Low quality of life subscore (domain Health and mobility)

Model 1: OR $(95 \% \mathrm{Cl}) \quad$ Model 2: OR $(95 \% \mathrm{Cl}) \quad$ Model 3: OR $(95 \% \mathrm{Cl})$

\begin{tabular}{|c|c|c|c|}
\hline \multicolumn{4}{|l|}{ Physical frailty (ref: non-frail) } \\
\hline Pre-frail & $3.14(2.19-4.50) * * *$ & $3.01(2.07-4.36) * * *$ & $1.97(1.31-2.94) * *$ \\
\hline Frail & $11.56(5.18-25.80) * * *$ & $11.22(4.88-25.81) * * *$ & $3.26(1.16-9.13) *$ \\
\hline Age & $1.02(0.90-1.15)$ & $1.02(0.90-1.15)$ & $1.01(0.88-1.16)$ \\
\hline Females (ref: males) & $1.54(1.06-2.23)^{*}$ & $1.51(0.99-2.28)$ & $1.51(0.97-2.35)$ \\
\hline Swiss citizenship (ref: no) & & $0.41(0.24-0.70) * *$ & $0.38(0.21-0.69) * *$ \\
\hline Living alone (ref: with others) & & $1.05(0.71-1.55)$ & $0.94(0.62-1.42)$ \\
\hline \multicolumn{4}{|l|}{ Education (ref: basic) } \\
\hline Apprenticeship & & $0.68(0.41-1.12)$ & $0.84(0.48-1.46)$ \\
\hline Post-compulsory & & $0.58(0.35-0.96) *$ & $0.73(0.42-1.30)$ \\
\hline Financial difficulties (ref: no) & & $1.01(0.57-1.79)$ & $0.96(0.52-1.78)$ \\
\hline Disability in BADLs (ref: no) & & & $3.45(2.23-5.33) * * *$ \\
\hline \multicolumn{4}{|l|}{ Medical conditions (ref: 0) } \\
\hline 1 & & & $1.31(0.78-2.20)$ \\
\hline$\geq 2$ & & & $1.43(0.85-2.42)$ \\
\hline Depression (ref: no) & & & $2.24(1.49-3.37) * * *$ \\
\hline MMSE & & & $0.93(0.85-1.02)$ \\
\hline
\end{tabular}

${ }^{*} \mathrm{P}<.05 ;{ }^{*} \mathrm{P}<.01 ;{ }^{* *} \mathrm{P}<.001 ; \mathrm{OR}=$ odds ratios; $\mathrm{Cl}=$ confidence intervals; $\mathrm{BADLs}=$ basic activities of daily living; $\mathrm{MMSE}=$ Mini-Mental State Examination; low quality of life defined as a score below the $1^{\text {st }}$ quintile. 
Appendix 2. (Continued)

Low quality of life subscore (domain Autonomy)

\section{Model 1: OR $(95 \% \mathrm{Cl}) \quad$ Model 2: OR $(95 \% \mathrm{Cl}) \quad$ Model 3: OR $(95 \% \mathrm{Cl})$}

\begin{tabular}{|c|c|c|c|}
\hline \multicolumn{4}{|l|}{ Physical frailty (ref: non-frail) } \\
\hline Pre-frail & $1.76(1.25-2.49) * *$ & $1.68(1.17-2.40) * *$ & $1.19(0.80-1.78)$ \\
\hline Frail & $4.94(2.23-10.90) * * *$ & $4.29(2.02-9.12) * * *$ & $1.79(0.75-4.25)$ \\
\hline Age & $0.91(0.80-1.03)$ & $0.90(0.79-1.02)$ & $0.88(0.77-1.00) *$ \\
\hline Females (ref: males) & $1.40(0.98-2.00)$ & $1.48(1.00-2.18) *$ & $1.38(0.92-2.09)$ \\
\hline Swiss citizenship (ref: no) & & $0.82(0.47-1.43)$ & $0.94(0.51-1.70)$ \\
\hline Living alone (ref: with others) & & $0.73(0.51-1.06)$ & $0.70(0.48-1.02)$ \\
\hline \multicolumn{4}{|l|}{ Education (ref: basic) } \\
\hline Apprenticeship & & $0.82(0.52-1.30)$ & $1.02(0.62-1.69)$ \\
\hline Post-compulsory & & $0.57(0.36-0.91) *$ & $0.74(0.45-1.23)$ \\
\hline Financial difficulties (ref: no) & & $2.18(1.37-3.46) * *$ & $2.24(1.38-3.63) * *$ \\
\hline Disability in BADLs (ref: no) & & & $1.51(0.95-2.40)$ \\
\hline \multicolumn{4}{|l|}{ Medical conditions (ref: 0) } \\
\hline 1 & & & $1.24(0.77-2.01)$ \\
\hline$\geq 2$ & & & $1.25(0.77-2.02)$ \\
\hline Depression (ref: no) & & & $2.80(1.89-4.13) * * *$ \\
\hline MMSE & & & $0.90(0.83-0.97) *$ \\
\hline
\end{tabular}

${ }^{*} \mathrm{P}<.05 ;{ }^{* *} \mathrm{P}<.01 ;{ }^{* * *} \mathrm{P}<.001 ; \mathrm{OR}=$ odds ratios; $\mathrm{Cl}=$ confidence intervals; $\mathrm{BADLs}=$ basic activities of daily living; MMSE = Mini-Mental State Examination; low quality of life defined as a score below the $1^{\text {st }}$ quintile. 
Appendix 2. (Continued)

\section{Low quality of life subscore (domain Close entourage)}

\section{Model 1: OR $(95 \% \mathrm{Cl}) \quad$ Model 2: OR $(95 \% \mathrm{Cl}) \quad$ Model 3: OR $(95 \% \mathrm{Cl})$}

\begin{tabular}{llll}
\hline Physical frailty (ref: non-frail) & & & \\
$\quad$ Pre-frail & $1.42(1.00-2.02)$ & $1.33(0.92-1.91)$ & $1.01(0.66-1.54)$ \\
$\quad$ Frail & $5.39(2.42-12.02) * * *$ & $4.80(2.16-10.64) * * *$ & $2.16(0.86-5.42)$ \\
Age & $0.92(0.81-1.03)$ & $0.91(0.80-1.03)$ & $0.91(0.80-1.03)$ \\
Females (ref: males) & $1.19(0.83-1.71)$ & $1.25(0.85-1.83)$ & $1.14(0.76-1.69)$ \\
Swiss citizenship (ref: no) & & $0.58(0.34-1.00)$ & $0.63(0.34-1.17)$ \\
Living alone (ref: with others) & & $0.93(0.64-1.36)$ & $0.90(0.61-1.32)$ \\
Education (ref: basic) & & \\
$\quad$ Apprenticeship & & $1.01(0.64-1.61)$ & $1.19(0.73-1.96)$ \\
$\quad$ Post-compulsory & $0.92(0.58-1.46)$ & $1.14(0.69-1.89)$ \\
Financial difficulties (ref: no) & & $2.05(1.28-3.28) * *$ & $2.12(1.27-3.52) * *$ \\
Disability in BADLs (ref: no) & & $1.21(0.75-1.95)$ \\
Medical conditions (ref: 0) & & \\
$\quad \begin{array}{l}\text { 1 } \\
\geq 2\end{array}$ & & $0.92(0.58-1.45)$ \\
Depression (ref: no) & & $0.85(0.52-1.38)$ \\
MMSE & & $3.44(2.25-5.26) * * *$ \\
\hline
\end{tabular}

${ }^{*} \mathrm{P}<.05 ;{ }^{* *} \mathrm{P}<.01 ;{ }^{* * *} \mathrm{P}<.001 ; \mathrm{OR}=$ odds ratios; $\mathrm{Cl}=$ confidence intervals; $\mathrm{BADLs}=$ basic activities of daily living; MMSE = Mini-Mental State Examination; low quality of life defined as a score below the $1^{\text {st }}$ quintile. 
Appendix 2. (Continued)

Low quality of life subscore (domain Material resources)

\section{Model 1: OR $(95 \% \mathrm{Cl}) \quad$ Model 2: OR $(95 \% \mathrm{Cl}) \quad$ Model 3: OR $(95 \% \mathrm{Cl})$}

\begin{tabular}{llll}
\hline Physical frailty (ref: non-frail) & & & \\
$\quad$ Pre-frail & $1.68(1.18-2.39)^{* *}$ & $1.46(1.00-2.14)^{*}$ & $1.14(0.76-1.73)$ \\
$\quad$ Frail & $2.98(1.37-6.48)^{* *}$ & $2.29(1.00-5.25)$ & $1.24(0.46-3.32)$ \\
Age & $1.03(0.91-1.16)$ & $1.02(0.89-1.16)$ & $1.00(0.87-1.14)$ \\
Females (ref: males) & $1.06(0.74-1.51)$ & $1.00(0.68-1.47)$ & $0.97(0.65-1.44)$ \\
Swiss citizenship (ref: no) & & $0.40(0.24-0.69)^{* *}$ & $0.42(0.24-0.74)^{* *}$ \\
Living alone (ref: with others) & & $0.94(0.64-1.38)$ & $0.91(0.61-1.36)$ \\
Education (ref: basic) & & \\
$\quad$ Apprenticeship & $0.49(0.31-0.79)^{* *}$ & $0.56(0.34-0.91)^{*}$ \\
$\quad$ Post-compulsory & $0.51(0.32-0.80)^{* *}$ & $0.61(0.37-0.99)^{*}$ \\
Financial difficulties (ref: no) & & $4.00(2.54-6.31)^{* * *}$ & $4.14(2.59-6.62)^{* * *}$ \\
Disability in BADLs (ref: no) & & $1.31(0.82-2.10)$ \\
Medical conditions (ref: 0) & & & \\
$\quad 1$ & & & $1.63(1.00-2.66)^{*}$ \\
$\geq 2$ & & $1.46(0.87-2.44)$ \\
Depression (ref: no) & & $1.78(1.16-2.72)^{* *}$ \\
MMSE & & $0.93(0.86-1.00)$ \\
\hline
\end{tabular}

${ }^{*} \mathrm{P}<.05 ;{ }^{* *} \mathrm{P}<.01 ;{ }^{* * *} \mathrm{P}<.001 ; \mathrm{OR}=$ odds ratios; $\mathrm{Cl}=$ confidence intervals; $\mathrm{BADLs}=$ basic activities of daily living; MMSE = Mini-Mental State Examination; low quality of life defined as a score below the $1^{\text {st }}$ quintile. 
Appendix 2. (Continued)

Low quality of life subscore (domain Esteem and recognition)

Model 1: OR $(95 \% \mathrm{Cl}) \quad$ Model 2: OR $(95 \% \mathrm{Cl}) \quad$ Model 3: OR $(95 \% \mathrm{Cl})$

\begin{tabular}{llll}
\hline Physical frailty (ref: non-frail) & & & \\
$\quad$ Pre-frail & $1.24(0.88-1.74)$ & $1.18(0.83-1.67)$ & $0.83(0.56-1.21)$ \\
$\quad$ Frail & $2.60(1.16-5.83)^{*}$ & $2.28(1.05-4.95)^{*}$ & $0.84(0.33-2.14)$ \\
Age & $0.97(0.86-1.10)$ & $0.97(0.86-1.10)$ & $0.97(0.86-1.10)$ \\
Females (ref: males) & $0.79(0.57-1.10)$ & $0.77(0.54-1.10)$ & $0.69(0.47-1.00)^{*}$ \\
Swiss citizenship (ref: no) & & $0.82(0.48-1.42)$ & $0.82(0.47-1.45)$ \\
Living alone (ref: with others) & $1.06(0.75-1.50)$ & $0.99(0.68-1.42)$ \\
Education (ref: basic) & & $1.15(0.72-1.84)$ \\
$\quad$ Apprenticeship & $1.02(0.65-1.58)$ & $0.90(0.56-1.44)$ \\
Post-compulsory & $0.80(0.52-1.24)$ & $1.62(1.02-2.57) *$ \\
Financial difficulties (ref: no) & & $1.61(1.03-2.51) *$ & $1.50(0.96-2.34)$ \\
Disability in BADLs (ref: no) & & $1.38(0.89-2.14)$ \\
Medical conditions (ref: 0) & & $1.40(0.89-2.21)$ \\
1 & & $3.08(2.10-4.53) * * *$ \\
$\geq 2$ & & $1.00(0.93-1.08)$ \\
Depression (ref: no) & & \\
MMSE & & & \\
\hline
\end{tabular}

${ }^{*} \mathrm{P}<.05 ;{ }^{* *} \mathrm{P}<.01 ;{ }^{* * *} \mathrm{P}<.001 ; \mathrm{OR}=$ odds ratios; $\mathrm{Cl}=$ confidence intervals; $\mathrm{BADLs}=$ basic activities of daily living; $\mathrm{MMSE}=$ Mini-Mental State Examination; low quality of life defined as a score below the $1^{\text {st }}$ quintile. 
Appendix 2. (Continued)

Low quality of life subscore (domain Social and cultural life)

Model 1: OR $(95 \% \mathrm{Cl}) \quad$ Model 2: OR $(95 \% \mathrm{Cl}) \quad$ Model 3: OR $(95 \% \mathrm{Cl})$

\begin{tabular}{|c|c|c|c|}
\hline \multicolumn{4}{|l|}{ Physical frailty (ref: non-frail) } \\
\hline Pre-frail & $1.72(1.23-2.42) * *$ & $1.66(1.17-2.34) * *$ & $1.26(0.85-1.87)$ \\
\hline Frail & $3.48(1.55-7.79) * *$ & $3.03(1.38-6.65) * *$ & $1.53(0.60-3.89)$ \\
\hline Age & $0.99(0.87-1.12)$ & $0.99(0.87-1.12)$ & $0.98(0.86-1.11)$ \\
\hline Females (ref: males) & $1.12(0.80-1.57)$ & $1.12(0.78-1.60)$ & $1.03(0.71-1.50)$ \\
\hline Swiss citizenship (ref: no) & & $0.77(0.44-1.34)$ & $0.78(0.44-1.39)$ \\
\hline Living alone (ref: with others) & & $0.94(0.66-1.32)$ & $0.90(0.63-1.29)$ \\
\hline \multicolumn{4}{|l|}{ Education (ref: basic) } \\
\hline Apprenticeship & & $1.04(0.68-1.60)$ & $1.19(0.75-1.89)$ \\
\hline Post-compulsory & & $0.43(0.27-0.69) * *$ & $0.48(0.29-0.80) * *$ \\
\hline Financial difficulties (ref: no) & & $1.29(0.80-2.10)$ & $1.25(0.76-2.06)$ \\
\hline Disability in BADLs (ref: no) & & & $1.46(0.91-2.33)$ \\
\hline \multicolumn{4}{|l|}{ Medical conditions (ref: 0) } \\
\hline 1 & & & $1.23(0.78-1.93)$ \\
\hline$\geq 2$ & & & $1.35(0.85-2.16)$ \\
\hline Depression (ref: no) & & & $2.17(1.46-3.21) * * *$ \\
\hline MMSE & & & $0.97(0.90-1.05)$ \\
\hline
\end{tabular}

${ }^{*} \mathrm{P}<.05 ;{ }^{* *} \mathrm{P}<.01 ;{ }^{* * *} \mathrm{P}<.001 ; \mathrm{OR}=$ odds ratios; $\mathrm{Cl}=$ confidence intervals; $\mathrm{BADLs}=$ basic activities of daily living; MMSE = Mini-Mental State Examination; low quality of life defined as a score below the $1^{\text {st }}$ quintile. 